\title{
Pre-Pregnancy BMI Influences the Association of Dietary Quality and Gestational Weight Gain: The SECOST Study
}

\author{
Heng Yaw Yong ${ }^{1}$, Zalilah Mohd Shariff ${ }^{1, *}$, Barakatun Nisak Mohd Yusof ${ }^{1}$, Zulida Rejali ${ }^{2}{ }^{\mathbb{D}}$, \\ Yvonne Yee Siang Tee ${ }^{3}$, Jacques Bindels ${ }^{4}$ and Eline M. van der Beek ${ }^{4,5}$ \\ 1 Department of Nutrition and Dietetics, Faculty of Medicine and Health Sciences, Universiti Putra Malaysia, \\ Seri Kembangan 43400, Malaysia; yong_hy@upm.edu.my (H.Y.Y.); bnisak@upm.edu.my (B.N.M.Y.) \\ 2 Department of Obstetrics and Gynecology, Faculty of Medicine and Health Sciences, Universiti Putra \\ Malaysia, Seri Kembangan 43400, Malaysia; zulida@upm.edu.my \\ 3 Danone Dumex (M) Sdn Bhd. Lot 759 (B3), Nilai Industrial Estate, Nilai 71800, Malaysia; \\ yvonneyeesiang.tee@danone.com \\ 4 Danone Nutricia Research, Uppsalalaan 12, 3584 CT Utrecht, The Netherlands; \\ jacques.bindels@danone.com (J.B.); eline.vanderbeek@danone.com (E.M.v.d.B.) \\ 5 Department of Pediatrics, University Medical Centre Groningen, University of Groningen, 9713 GZ \\ Groningen, The Netherlands \\ * Correspondence: zalilahms@upm.edu.my
}

Received: 20 August 2019; Accepted: 30 September 2019; Published: 4 October 2019

\begin{abstract}
Poor diet quality in pregnancy could impact gestational weight gain (GWG) and consequently fetal growth and development. But today there is limited data available on gestational diet quality. This study investigated the association between diet quality in each pregnancy trimester and GWG in Malaysian women. Diet quality was assessed using the modified Healthy Eating Index for Malaysians (HEI). Total GWG was defined as the difference between measured weight at last prenatal visit and pre-pregnancy weight. About one-fourth of women $(23.3 \%)$ had excessive total GWG. There were significant differences in the HEI component score across trimesters, except for fruits. Overall, overweight/obese women had lower total HEI score (51.49-55.40) during pregnancy compared to non-overweight/obese women (53.38-56.50). For non-overweight/obese women, higher total HEI scores in the second and third trimesters were significantly associated with lower risk of inadequate GWG $(\mathrm{aOR}=0.97,95 \% \mathrm{CI}=0.95-0.99, p=0.01)$ and higher risk of excessive GWG $(\mathrm{aOR}=1.04,95 \% \mathrm{CI}=1.01-1.07, p=0.03)$, respectively. Overweight/obese women with higher total HEI scores in the second $(\mathrm{aOR}=1.04,95 \% \mathrm{CI}=1.01-1.07, p=0.02)$ and third trimester $(\mathrm{aOR}=1.04$, $95 \% \mathrm{CI}=1.01-1.08, p=0.02$ ) were significantly at higher risk for excessive GWG. Pregnant women had relatively low diet quality throughout pregnancy. Diet quality and GWG association differed according to pre-pregnancy BMI with excessive GWG more likely to be associated with higher total HEI scores in the third trimester.
\end{abstract}

Keywords: diet quality; healthy eating index (HEI); gestational weight gain (GWG); pre-pregnancy BMI

\section{Introduction}

To date, there is no Asian-specific gestational weight gain (GWG) guideline. With the exception of Japan, most Asian countries use the Institute of Medicine (IOM) GWG guideline [1]. In 2009, the US Institute of Medicine (IOM) established updated guidelines for weight gain during pregnancy, recommending that GWG should be based on pre-pregnancy BMI. Pregnant women with high 
pre-pregnancy BMI should gain less weight in pregnancy than those with a lower pre-pregnancy BMI. Nevertheless, most studies showed that overweight or obese women tend to gain above the recommended range, while underweight women were more likely to have inadequate GWG [2,3]. Previous studies in Malaysia have shown that more than one-third of pregnant women were overweight or obese, and more than half of these women had excessive GWG [4,5]. It is well-documented that excessive GWG is associated with increased risk of adverse pregnancy and birth outcomes [6].

Diet quality indices are increasingly being used to determine associations between dietary intake with nutritional status and health outcomes [7]. Such indices measure how well the diets conform to the recommendations based on national dietary guidelines [8]. Generally, pregnant women who consume sufficient amounts of food tend to have better nutritional status and pregnancy outcomes [9]. Nonetheless, it is also crucial for pregnant women to consider the overall quality of their diet. As there are variations in dietary guidelines across countries and cultural differences in population diets, several versions of diet quality indices for pregnant women have been developed [10-12]. Most studies on diet quality of pregnant women described the diet quality in specific trimester of pregnancy (early pregnancy or 26-28th weeks) [13-15] and determined its associated factors [14,16,17]. However, limited studies examined diet quality for each trimester $[17,18]$ and the possible association between diet quality and GWG $[15,19]$. As diets of women tend to change over the course of pregnancy, it is important to assess the diet quality of women in each trimester separately, as the they might have different implications for pregnancy outcomes.

Both excessive and inadequate GWG can have negative consequences on pregnancy and birth outcomes [20]. Mothers with inadequate GWG have higher risk for seizure, longer hospital stay, miscarriage, and delivery of small-for-gestational (SGA) infants [21-23]. Excessive GWG is associated with increased risk for caesarean delivery, preeclampsia, and large-for-gestational-age (LGA) births [21, 24-26]. Both situations may also have long term implications for growth and development and the risk for disease later in life $[27,28]$. Thus, it is crucial for child-bearing age women to adopt and maintain healthy eating habits to ensure healthy pre-pregnancy BMI and achieve optimal GWG during pregnancy. Improvements in women's health and related behaviors are likely to have benefits not only for their own health but also for the health of their offspring. Unlike many other risk factors that vary by socioeconomic position, dietary intake is modifiable. This study described the diet quality of Malaysian women during pregnancy that reflects the national dietary guidelines, and its association with total GWG, observing differential effects of diet quality in the first, second and third trimester on total GWG.

\section{Materials and Methods}

\subsection{Study Design and Location}

SECOST (Seremban Cohort Study) is a prospective study in which pregnant women were followed-up through 1 year postpartum, and their infants were followed-up every six months until two years of age. Women in the first trimester (10-13th weeks of gestation) of pregnancy were recruited from three Maternal and Child Health $(\mathrm{MCH})$ clinics in Seremban District, Negeri Sembilan, Malaysia.

\subsection{Measurements}

All women were interviewed by trained enumerators using a pre-tested questionnaire. Details of the instrument have been published elsewhere [29]. The instruments were pre-tested prior to data collection as to ensure the appropriateness, clarify and interpretation of the instruments. Socio-demographic information obtained included current age, education level, ethnicity, occupation status, monthly household income, and household size. Obstetrical information (e.g., gravidity and parity) were obtained from medical records. 


\subsection{Dietary Assessment}

A one-day, 24-h dietary recall was used to obtain food intakes of respondents at each trimester. Women were required to recall all food and beverages consumed in the past $24 \mathrm{~h}$. The recall form consisted of types of food and beverages, time of eating or drinking, food ingredients, preparation methods, and quantity of foods and beverages consumed. Standard calibrated household measuring cups, glasses, bowls, and spoons were used to assist the respondents in recalling the portion size of food and beverages consumed. Dietary data were analyzed using Nutritionist Pro Diet Analysis software: Version 1.5 (Axxya Systems, CA, USA) [30]. Food intake data were also presented as number of servings consumed from each food group based on the Malaysian Food Guide Pyramid [31].

\subsection{Healthy Eating Index (HEI)}

Diet quality of pregnant women was assessed using the modified Healthy Eating Index for Malaysians (HEI) (Table S1). The HEI comprised nine components, each representing different aspects of a healthful diet. Components 1-7 measured the person's degree of compliance with the seven major food groups: Cereals and grains, vegetables, fruits, milk and milk products, poultry, meat and egg, fish and seafood, and legumes, recommended by Malaysian Dietary Guidelines 2010 for Malaysian (MDG). Component 8-9 measured the compliance with the recommendation of the percentage of energy from fat, and total sodium intake by MDG [31]. Each component has a maximum score of 10 for full compliance and a minimum score of 0 for lack of compliance. The score for each component was calculated using the formula: (Actual serving consumed based on respondent's diet recall/ recommended serving size based on MDG) and multiplied by 10 . If an individual consumed less than the recommended amount of servings, the score was calculated with the following formula: $10 \times$ (the consumed amount of servings)/ (the lower limit of the recommended serving). If an individual consumed more than the recommended amount of servings, the score was calculated with the following formula: $10-10 \times$ [(the consumed servings) - (the upper limit of the recommended servings)]/(the upper limit of the recommended serving). Each score was rounded off to the nearest whole number. When this calculation produced a negative score because of excess servings, the score was converted to 0 . The score was calculated proportionately for the in-between responses [8,32]. Total HEI score was calculated by summing up the score of each component. The possible score for total HEI ranges from 0 to 100. A higher score indicates an intake close to the recommended range, while a lower score reflects less compliance with recommended intakes.

\subsection{Anthropometric Measurements}

Maternal height was measured at study enrolment, while weight was measured at each study visits using a standard instrument (SECA digital weighing scale and SECA body meter) and standard procedures. Women were requested to recall pre-pregnancy body weight (current pregnancy). Pre-pregnancy BMI was calculated from height and weight and categorized using World Health Organization (WHO)'s cut-off points respectively: Underweight $\left(<18.5 \mathrm{~kg} / \mathrm{m}^{2}\right)$, normal weight $\left(18.5-24.9 \mathrm{~kg} / \mathrm{m}^{2}\right)$, overweight $\left(25.0-29.9 \mathrm{~kg} / \mathrm{m}^{2}\right)$, and obese $\left(\geq 30.0 \mathrm{~kg} / \mathrm{m}^{2}\right)$ [33]. Weight in the first, second and third trimester was measured as the closest measurement to 12th weeks of gestation (10-13th weeks), the closest measurement to 26 weeks of gestation (range 24-32nd weeks), and the closest measurement to 38 weeks of gestation (range 34-38th weeks). Total GWG was defined as the difference between the measured weight at last prenatal visit and the pre-pregnancy weight. Rate of GWG in the second trimester and third trimester was defined as the average weekly weight gain in that trimester and was then categorized as inadequate, adequate, or excessive for each category of pre-pregnancy BMI [34]. Total GWG in relation to pre-pregnancy BMI was then classified as gaining below (inadequate GWG), within (adequate GWG), or above (excessive GWG) the recommendation of IOM [34]. 


\subsection{Other Variables}

The Pregnancy Physical Activity Questionnaire (PPAQ) was used to determine the physical activity level of pregnant women [35]. PPAQ consisted of items on the frequency and intensity of physical activity (PA), frequency of vigorous PA, hours spent on vigorous PA, the average duration of a PA session. Total activity was calculated as the sum of all intensity activities and type scores. A metabolic equivalent (MET) hours per week was calculated by multiplying the duration of time spent in each activity with an established MET value.

\subsection{Statistical Analysis}

All statistical analyses were performed using IBM SPSS Statistics for Windows, Version 25.0 (IBM, New York, USA) [36]. Continuous variables were expressed as the means and standard deviations, while categorical variables as absolute frequencies and percentages. Multinomial logistic regression was performed to determine the associations between diet quality in each trimester and total GWG adjusted for covariates. Covariates (continuous variables) included were age, years of education, parity, physical activity level, and pre-pregnancy BMI. Given the possibility of an interaction effect between age, years of education, parity, physical activity, and pre-pregnancy BMI with diet quality, models incorporating interaction terms were also performed. Analysis of covariance (ANCOVA) with Bonferroni correction for multiple comparisons was used to determine the associations between diet quality and total GWG stratified by pre-pregnancy BMI categories (non-overweight/obese vs. overweight/obese). Statistical significance was set at $p<0.05$.

\section{Results}

Table 1 presents the characteristics of women. The mean age of the women was $30.16 \pm 4.51$ years, with $52.3 \%$ aged over 30 years. Most of the women were Malay $(89.0 \%)$, had secondary or lower education $(46.0 \%)$, were employed $(69.2 \%)$, and had low monthly household income $(63.5 \%)$. The mean gravidity and parity of women were $2.46 \pm 1.48$, and $1.22 \pm 1.29$, respectively. About $7.5 \%$ of women had a medical history of GDM and more than one-fourth had a family history of diabetes mellitus $(26.9 \%)$. The mean pre-pregnancy weight and pre-pregnancy BMI were $59.11 \pm 13.57 \mathrm{~kg}$ and $24.10 \pm 5.06 \mathrm{~kg} / \mathrm{m}^{2}$, respectively. More than half $(53.1 \%)$ had normal pre-pregnancy BMI $\left(18.50-24.99 \mathrm{~kg} / \mathrm{m}^{2}\right)$, while about $22.3 \%$ and $14.4 \%$ were categorized as overweight and obese respectively. The mean total energy expenditure in the second and third trimester was $264.58 \pm 118.06$ Mets hours/week and $249.56 \pm 107.36$ Mets hours/week, respectively. This finding was slightly higher than those reported in previous studies [37-39].

The overall mean rate of GWG at third trimester $(0.39 \pm 0.01 \mathrm{~kg} /$ week $)$ was slightly higher than the second trimester $(0.37 \pm 0.01 \mathrm{~kg} /$ week) (Table 2). The mean total GWG was $11.06 \pm 0.23 \mathrm{~kg}$. Most of the underweight $(89.8 \%)$ and normal weight $(95.5 \%)$ women had inadequate to adequate total GWG. About $43.9 \%$ of overweight women had adequate total GWG. Among obese women, more than half (52.2\%) had excessive total GWG.

The mean total HEI scores and HEI component score for the first, second and third trimester are presented in Table 3. The mean total HEI score in the first $(52.73 \pm 0.52)$ and the third trimester $(52.76 \pm 0.52)$ were almost similar. The HEI score has improved at the second trimester with the HEI score of $57.10 \pm 0.52$. There were significant differences in HEI component scores across trimesters, except for fruits. Women had higher HEI score for cereals and grains (7.53-8.54), poultry, meat, and egg (7.52-8.55) and sodium (7.04-8.61), but lower HEI score for legumes (1.04-3.14) and milk and milk products (1.96-3.82). 
Table 1. Characteristics of women $(n=480)$.

\begin{tabular}{|c|c|c|}
\hline Variables & $n(\%)$ & Mean \pm SD \\
\hline Age (years) & & $30.16 \pm 4.51$ \\
\hline$\leq 30$ & $229(47.7)$ & \\
\hline$>30$ & $251(52.3)$ & \\
\hline \multicolumn{3}{|l|}{ Ethnicity } \\
\hline Malay & $427(89.0)$ & \\
\hline Non-Malay & $53(11.0)$ & \\
\hline Education level (years) & & $12.95 \pm 2.41$ \\
\hline Secondary and lower & $221(46.0)$ & \\
\hline STPM/ matric/ diploma/ certificate & $157(32.7)$ & \\
\hline Tertiary and above & $102(21.3)$ & \\
\hline \multicolumn{3}{|l|}{ Occupation status } \\
\hline Unemployed & $148(30.8)$ & \\
\hline Employed & $332(69.2)$ & \\
\hline Monthly household income (RM) ${ }^{1}$ & & $3698.30 \pm 2034.20$ \\
\hline Low $(<3860)$ & $305(63.5)$ & \\
\hline Middle (3860-8319) & $161(33.5)$ & \\
\hline High $(\geq 8320)$ & $14(2.9)$ & \\
\hline Household size & & $3.78 \pm 1.63$ \\
\hline$\leq 2$ & $116(24.2)$ & \\
\hline $3-4$ & $240(50.0)$ & \\
\hline$\geq 5$ & $124(25.8)$ & \\
\hline Gravidity & & $2.46 \pm 1.48$ \\
\hline 1 & 155 (32.3) & \\
\hline 2 & $132(27.5)$ & \\
\hline$\geq 3$ & $193(40.2)$ & \\
\hline Parity & & $1.22 \pm 1.29$ \\
\hline 0 & $176(36.7)$ & \\
\hline $1-2$ & $229(47.7)$ & \\
\hline$\geq 3$ & $75(15.6)$ & \\
\hline \multicolumn{3}{|l|}{ Medical history of GDM } \\
\hline No & $444(92.5)$ & \\
\hline Yes & $36(7.5)$ & \\
\hline \multicolumn{3}{|l|}{ Family history of diabetes mellitus } \\
\hline No & $351(73.1)$ & \\
\hline Yes & $129(26.9)$ & \\
\hline Height (m) & & $1.56 \pm 0.06$ \\
\hline$<1.55$ & $176(36.7)$ & \\
\hline $1.55-1.58$ & $144(30.0)$ & \\
\hline$\geq 1.59$ & $160(33.3)$ & \\
\hline Pre-pregnancy weight (kg) & & $59.11 \pm 13.57$ \\
\hline Pre-pregnancy BMI $\left(\mathrm{kg} / \mathrm{m}^{2}\right)$ & & $24.10 \pm 5.06$ \\
\hline Underweight $(<18.5)$ & $49(10.2)$ & \\
\hline Normal (18.5-24.9) & $255(53.1)$ & \\
\hline Overweight (25.0-29.9) & $107(22.3)$ & \\
\hline Obese $(\geq 30.0)$ & $69(14.4)$ & \\
\hline \multicolumn{3}{|l|}{ Physical activity (MET-hours/week) } \\
\hline 2nd trimester & & $264.58 \pm 118.06$ \\
\hline 3rd trimester & & $249.56 \pm 107.36$ \\
\hline
\end{tabular}

${ }^{1}$ 10th Malaysia Plan, 1 USD = RM 4.18. 
Table 2. Gestational weight gain (GWG) of women by pre-pregnancy BMI $(n=480)$.

\begin{tabular}{|c|c|c|c|c|c|c|c|}
\hline \multirow{3}{*}{ Pre-pregnancy BMI $\left(\mathrm{kg} / \mathrm{m}^{2}\right)^{1}$} & \multirow{3}{*}{$\begin{array}{c}\text { GWG in kg } \\
\text { 1st Trimester } \\
\text { Median (IQR) }\end{array}$} & \multicolumn{2}{|c|}{ Rates of GWG in kg/week ${ }^{2,3}$} & \multirow{2}{*}{\multicolumn{4}{|c|}{ Total Weight Gain in $\mathrm{kg}^{2,3}$}} \\
\hline & & 2nd Trimester & 3rd Trimester & & & & \\
\hline & & \multicolumn{2}{|c|}{ Mean \pm SD } & Mean \pm SD & I & $\mathbf{A}$ & E \\
\hline Underweight $(n=49)$ & $3.00(4.25)$ & $0.46 \pm 0.02$ & $0.40 \pm 0.03$ & $12.93 \pm 0.54$ & $22(44.9)$ & $22(44.9)$ & $5(10.2)$ \\
\hline Normal weight $(n=255)$ & $2.00(3.50)$ & $0.41 \pm 0.01$ & $0.43 \pm 0.02$ & $11.90 \pm 0.29$ & $115(51.1)$ & $100(44.4)$ & $40(4.5)$ \\
\hline Overweight $(n=107)$ & $2.00(4.00)$ & $0.31 \pm 0.02$ & $0.32 \pm 0.03$ & $9.49 \pm 0.42$ & $29(27.1)$ & 47 (43.9) & $31(29.0)$ \\
\hline Obese $(n=69)$ & $2.00(5.05)$ & $0.28 \pm 0.03$ & $0.36 \pm 0.04$ & $9.03 \pm 0.73$ & $15(21.7)$ & $18(26.1)$ & $36(52.2)$ \\
\hline Total $(n=480)$ & $2.00(4.00)$ & $0.37 \pm 0.01$ & $0.39 \pm 0.01$ & $11.06 \pm 0.23$ & $181(37.7)$ & $187(39.0)$ & $112(23.2)$ \\
\hline
\end{tabular}

Rate of weight gain was defined as average weekly weight gain in that particular trimester of pregnancy. Total weight gain was defined as the difference between the weight at last prenatal visit and pre-pregnancy weight. ${ }^{1}$ Based on IOM recommended range for weight gain during pregnancy (2009). ${ }^{2}$ Underweight $(<18.5)$; normal weight (18.5-24.9); overweight (25.0-29.9); obese ( $\geq 30.0) .{ }^{3} \mathrm{I}=$ inadequate; $\mathrm{A}=$ adequate; $\mathrm{E}=$ excessive.

Table 3. Component score and total score for Healthy Eating Index for Malaysians (HEI) by trimester of pregnancy.

\begin{tabular}{|c|c|c|c|c|c|c|c|}
\hline \multirow{2}{*}{ Variables } & \multirow{2}{*}{$\begin{array}{l}\text { Possible Range } \\
\text { of Score }\end{array}$} & 1st Trimester & 2nd Trimester & 3rd Trimester & \multirow{2}{*}{$\mathbf{F}$} & \multirow{2}{*}{$p$-Value } & \multirow{2}{*}{$\begin{array}{c}p \text {-Value } \\
\text { for Trend }\end{array}$} \\
\hline & & \multicolumn{3}{|c|}{ Mean \pm SE } & & & \\
\hline \multicolumn{8}{|l|}{ HEI component } \\
\hline Cereals and grains & 0 to 10 & $8.54 \pm 0.09^{a, b}$ & $9.37 \pm 0.09^{a, c}$ & $7.53 \pm 0.09^{b, c}$ & 97.63 & $0.001 *$ & $0.001 *$ \\
\hline Vegetables & 0 to 10 & $3.03 \pm 0.14^{\mathrm{a}, \mathrm{b}}$ & $4.20 \pm 0.14^{\mathrm{a}}$ & $4.14 \pm 0.14^{\mathrm{b}}$ & 21.75 & 0.001 * & 0.001 * \\
\hline Fruits & 0 to 10 & $3.43 \pm 0.18$ & $4.00 \pm 0.18$ & $3.67 \pm 0.18$ & 2.55 & 0.07 & 0.35 \\
\hline Poultry, meat and egg & 0 to 10 & $8.48 \pm 0.14^{b}$ & $8.55 \pm 0.14^{c}$ & $7.52 \pm 0.14^{b, c}$ & 16.06 & $0.001 *$ & $0.001 *$ \\
\hline Fish and seafood & 0 to 10 & $5.83 \pm 0.20^{\mathrm{a}}$ & $6.84 \pm 0.20^{\mathrm{a}, \mathrm{c}}$ & $5.93 \pm 0.20^{c}$ & 7.60 & $0.001 *$ & 0.72 \\
\hline Legumes & 0 to 10 & $2.20 \pm 0.17^{\mathrm{a}, \mathrm{b}}$ & $1.04 \pm 0.16^{a, c}$ & $3.14 \pm 0.17^{b, c}$ & 40.96 & $0.001 *$ & 0.001 * \\
\hline Milk and milk products & 0 to 10 & $1.96 \pm 0.15^{a, b}$ & $3.82 \pm 0.15^{a, c}$ & $2.73 \pm 0.15^{b, c}$ & 38.78 & $0.001 *$ & $0.001 *$ \\
\hline$\%$ of energy from total fat & 0 to 10 & $5.37 \pm 0.21^{b}$ & $5.59 \pm 0.21^{b}$ & $4.68 \pm 0.21 \mathrm{~b}, \mathrm{c}$ & 5.23 & $0.01 *$ & $0.02 *$ \\
\hline Sodium & 0 to 10 & $8.61 \pm 0.14^{\mathrm{a}, \mathrm{b}}$ & $7.04 \pm 0.14^{\mathrm{a}, \mathrm{c}}$ & $7.77 \pm 0.14^{b, c}$ & 31.57 & $0.001 *$ & $0.001 *$ \\
\hline Total HEI & 0 to 100 & $52.73 \pm 0.52^{\mathrm{a}}$ & $56.10 \pm 0.52^{a, c}$ & $52.76 \pm 0.52^{c}$ & 14.01 & $0.001 *$ & $0.001 *$ \\
\hline
\end{tabular}

Adjusted by age, years of education, parity, total GWG, physical activity level (MET-hours/week) and pre-pregnancy BMI. Means with similar superscripts in the same row indicate a significant difference $(p<0.05)$ : ${ }^{\text {a }}$ first trimester vs. second trimester; ${ }^{\mathrm{b}}$ first trimester vs. third trimester; ${ }^{\mathrm{c}}$ second trimester vs. third trimester. ${ }^{*} p<0.05$.

Table 4 shows the adjusted odds ratio for associations between diet quality and total GWG. Women with higher total HEI score in the second trimester had significantly lower risk of inadequate GWG $(\mathrm{aOR}=0.98,95 \% \mathrm{CI}=0.96-0.98)$ after adjusted for covariates. Meanwhile, women with higher total HEI score in the third trimester were at significantly higher risk of excessive GWG (aOR $=1.04,95 \%$ $\mathrm{CI}=1.04,95 \% \mathrm{CI}=1.01-1.06)$ after adjusted for covariates. The likelihood ratio test revealed that only pre-pregnancy BMI showed significant interactions with total HEI score in second $\left(\chi^{2}=33.38, p<0.01\right)$ and third trimester $\left(\chi^{2}=42.08, p<0.01\right)$ to the risk of excessive GWG. The mean total HEI score for non-overweight/obese women at the first, second, and third trimester were $53.45 \pm 0.68,56.50 \pm 0.64$ and $53.38 \pm 0.64$, respectively. Overall, a significantly lower total HEI score across trimesters of pregnancy was found among overweight/obese women with the mean total HEI score of $51.48 \pm 0.84,55.40 \pm 0.89$ and $51.69 \pm 0.81$ for the first, second and third trimester $(\mathrm{F}=15.05, p=0.03)$.

Table 4. Adjusted OR for associations between total HEI score in each trimester and GWG.

\begin{tabular}{|c|c|c|c|c|}
\hline \multirow{2}{*}{ Diet Quality } & \multicolumn{2}{|c|}{ Inadequate GWG } & \multicolumn{2}{|c|}{ Excessive GWG } \\
\hline & aOR $(95 \% \mathrm{CI})$ & $p$-Value & aOR $(95 \% \mathrm{CI})$ & $p$-Value \\
\hline \multicolumn{5}{|l|}{ Total HEI score } \\
\hline 1st trimester & $1.01[0.99-1.02]$ & 0.68 & $1.02[0.99-1.03]$ & 0.52 \\
\hline 2nd trimester & $0.98[0.96-0.98]$ & $0.03 *$ & $1.01[0.98-1.03]$ & 0.33 \\
\hline 3rd trimester & $0.99[0.97-1.01]$ & 0.60 & $1.04[1.01-1.06]$ & $0.01 *$ \\
\hline \multicolumn{5}{|l|}{ Interaction term ${ }^{1}$} \\
\hline Pre-pregnancy BMI x total HEI score (1st trimester) & $1.01[0.99-1.00]$ & 0.37 & $1.01[0.99-1.03]$ & 0.90 \\
\hline Pre-pregnancy BMI $x$ total HEI score (2nd trimester) & $0.99[0.99-1.00]$ & 0.05 & $1.01[1.01-1.02]$ & $0.001 * *$ \\
\hline Pre-pregnancy BMI x total HEI score (3rd trimester) & $1.02[0.99-1.01]$ & 0.51 & $1.02[1.01-1.04]$ & $0.001 * *$ \\
\hline
\end{tabular}

Note. aOR- adjusted odds ratio and $95 \%$ CI. Adequate GWG as reference group. Adjusted by age, years of education, parity, physical activity level (MET-hours/week) and pre-pregnancy BMI. ${ }^{1}$ Only pre-pregnancy BMI showed significant interaction between HEI and GWG. ${ }^{*} p<0.05,{ }^{* *} p<0.001$. 
The associations between total HEI score in each trimester and total GWG by pre-pregnancy BMI are shown in Table 5. Non-overweight/obese women with a higher total HEI score in the second trimester had lower risk of inadequate GWG (Aor $=0.97,95 \% \mathrm{CI}=0.95-0.99$ ) but a higher total HEI score in the third trimester was significantly associated with higher risk of excessive GWG in this group $(\mathrm{aOR}=1.04,95 \% \mathrm{CI}=1.01-1.07)$. For overweight/obese women, higher total HEI scores in both second $(\mathrm{aOR}=1.01,95 \% \mathrm{CI}=1.01-1.02)$ and third trimesters $(\mathrm{aOR}=1.04,95 \% \mathrm{CI}=1.01-1.04)$ were significantly associated with higher risk for GDM.

Table 5. Adjusted OR for associations between total HEI score in each trimester and GWG stratified by pre-pregnancy BMI.

\begin{tabular}{lcccc}
\hline \multirow{2}{*}{ Diet Quality } & \multicolumn{2}{c}{ Inadequate GWG } & \multicolumn{2}{c}{ Excessive GWG } \\
\cline { 2 - 5 } & aOR [95\% CI] & $p$-Value & aOR [95\% CI] & $p$-Value \\
\hline $\begin{array}{l}\text { Non-overweight/obese }(n=304) \\
\text { Total HEI }\end{array}$ & & & & \\
$\quad$ 1st trimester & $1.01[0.98-1.03]$ & 0.74 & $1.02[0.99-1.05]$ & 0.34 \\
$\quad$ 2nd trimester & $0.97[0.95-0.99]$ & $0.01 *$ & $0.99[0.96-1.02]$ & 0.44 \\
$\quad$ 3rd trimester & $0.99[0.97-1.01]$ & 0.27 & $1.04[1.01-1.07]$ & $0.03 *$ \\
Overweight/obese $(n=176)$ & & & & \\
Total HEI & $1.01[0.97-1.04]$ & 0.69 & $0.99[0.97-1.03]$ & 0.95 \\
$\quad$ 1st trimester & $1.00[0.96-1.03]$ & 0.82 & $1.04[1.01-1.07]$ & $0.02 *$ \\
2nd trimester & $1.01[0.97-1.05]$ & 0.50 & $1.04[1.01-1.08]$ & $0.02 *$ \\
$\quad$ 3rd trimester &
\end{tabular}

Note. aOR- adjusted odds ratio and 95\% CI. Adequate GWG was used as reference group. Adjusted by age, years of education, parity, and physical activity level (MET-hours/week). ${ }^{*} p<0.05$.

\section{Discussion}

The present study showed that non-overweight/obese women with higher total HEI scores in the second trimester showed a lower risk for inadequate GWG, yet higher total HEI scores in the third trimester were significantly associated with a higher risk of excessive GWG. Further analysis to determine the components of HEI that were associated with GWG among this group of non-overweight/obese women showed that in particular higher intakes of cereals and grains in the second trimester was associated with a significantly lower risk of inadequate GWG (aOR $=0.71,95 \%$ $\mathrm{CI}=0.55-0.92, p<0.05)$. Although carbohydrates are an important component of a healthy diet during pregnancy [40], its association with GWG has been inconsistent [41,42] which could be related to the type and quality of carbohydrate. Carbohydrate sources with lower glycemic index (GI) such as whole grains, contribute to lower energy density, increased satiety, and subsequently adequate GWG; conversely, carbohydrate sources with higher GI such as refined grains (e.g. desserts, and sweet snacks) tend to be high in energy density and could contribute to higher GWG [43]. The cereals and grains commonly consumed by women in this study included rice, noodles and pasta, bread, cereal, and cereals products, which are considered as good carbohydrate sources. Nevertheless, further studies are needed to confirm the reported associations and to determine which food types in cereals and grains group contribute to (adequate) GWG.

While overweight/obese women with higher total HEI scores in the second and third trimester had a higher risk for excessive GWG, non-overweight/obese women with higher total HEI scores in the third trimester were also more likely to have excessive GWG. Analyses of HEI components revealed that overweight/obese women with higher intakes of fruits in the second (aOR $=1.19,95 \%$ $\mathrm{CI}=1.07-1.32, p<0.05)$ and the third trimester $(\mathrm{aOR}=1.13,95 \% \mathrm{CI}=1.03-1.24, p<0.05)$, as well as higher intakes of milk and milk products in the third trimester $(\mathrm{aOR}=1.03,95 \% \mathrm{CI}=1.01-1.31$, $p<0.05$ ) had significant risk for excessive GWG. Similarly, normal weight with higher intakes of fruits $(\mathrm{aOR}=1.03,95 \% \mathrm{CI}=1.01-1.15, p<0.05)$ and milk and dairy products $(\mathrm{aOR}=1.06,95 \% \mathrm{CI}=1.02-1.19$, $p<0.05)$ in the third trimester were more likely to have excessive GWG. In this sample of pregnant women, frequently consumed fruits were bananas, grapes, mangos, dates, raisins, and durian. Milk 
and milk products include milk, ice-cream, and cheese. Although women in this study had low HEI component scores for fruits, vegetables and milk/milk products, the nutrient content and methods of food preparation could contribute to the energy density of the foods. The commonly consumed fruits are not only relatively high in sugar, particularly if consumed in large amount, but also are frequently consumed as juices/shakes/blended ice/traditional sweet desserts with added sugar. Similarly, milk may be consumed as plain but could also be a flavoured milk or may be added to beverages such as sugar added tea and coffee, milk shakes and malted drinks. Although not all types of milk products have high energy and fat/sugar contents, low fat, and low-sugar ice-creams and low-fat cheeses are not commonly available in the market. Thus, choosing high energy dense foods (high sugar and/or fat) may result in an increased daily total intake of calories which could contribute to higher weight gain.

The mean total HEI score (52.76-56.10) for pregnant women in this study was substantially lower than those reported in Western countries (62.9-70.2) [16,17,44,45] but almost parallel to those in other Asian countries, such as Singapore (52.4) [13] and Indonesia (58.9) [15]. Cross-study variations in HEI scores could be explained by the differences in study design, measurement of dietary intake (e.g., diet recall, diet history, food frequency questionnaire), socio-demographic background (e.g., age, ethnicity, and nutritional knowledge) and food environment (e.g., accessibility to fast food, convenience store and food court setting). Based on the analyses of HEI components, women in the present study had low HEI component score for legumes and milk and milk products, with the average score ranging from 1.04 to 3.83. This is consistent with the findings of a review and meta-analysis on energy and macronutrient intakes of Malaysian adults which showed that most Malaysians did not meet the recommended servings for other protein sources specifically legumes, nuts, milk and milk products [46].

A recent study by Savard et al. (2019) showed that there was no significant variation in overall diet quality across all trimesters of pregnancy among Canadian pregnant women. For HEI component analysis, intake of fruits and vegetables decreased significantly throughout pregnancy, but intake of milk and milk products increased significantly across trimester [17]. In contrast, Moran et al. (2013) reported an overall decrease in maternal diet quality during pregnancy in overweight/obese women [18]. However, the present study highlights that there was significant variation in the total HEI score across all trimesters of pregnancy, whereby total HEI score increased significantly from the first to the second trimester and then decreased in the third trimester to a level that was similar in the first trimester. Given that this change occurred in the context of a relatively low total HEI score, this finding should be interpreted with caution. A possible explanation for the increase in the total HEI scores from the first to the second trimester could be due to the resolution of nausea or vomiting after the first trimester or the positive dietary changes after receiving nutrition advice during early pregnancy [18]. Although pregnancy is known to be a period during which pregnant women are motivated to adopt healthy behaviors, it is also possible that motivation decreases as pregnancy progresses, making it difficult for women to maintain high quality of their diets.

At present, there is no standard indicator or measure of diet quality. The HEI was established by the United States Department of Agriculture (USDA) in 1995 to measure how well the diet conforms to the national dietary guidelines [8]. It has been widely used as a measure of diet quality in all life stages [47,48], including pregnancy and in relation to various health or disease outcomes [49-51]. As dietary guidelines vary by countries and cultures, several versions of HEI for pregnant women have been developed [10-12]. The HEI-1995, HEI-2005, and the Alternate Healthy Eating Index for Pregnancy (AHEI-P) are commonly used diet quality indexes for the US pregnant women [12,16,52-54]. Asian countries, such as China [55], Singapore [13], and Indonesia [15] have adapted the HEI and AHEI-P to the local dietary guidelines. These measures of HEI were also associated with sociodemographic characteristics $[53,54,56]$, pre-pregnancy weight status [12,16], and birth outcomes $[46,57,58]$. The HEI for Malaysians used in this study showed an association with GWG, thus, giving support to HEI as a good indicator of diet quality in this study population.

This study has several limitations. Respondents were not representative of the general population of pregnant women in Malaysia. Most women were Malay, had secondary education and lower, and 
were of low- and middle-income households. Besides recall bias due to self-report, the use of one 24-h dietary recall to assess diet quality of pregnant women might not represent the usual intake of pregnant women. To prevent under-reporting, albums of foods and beverages and household measurements were used to assist the respondents' recall of dietary intake. The present study was limited to describing diet quality and its association to GWG and did not explore factors (e.g. socioeconomic position, food environment, motivation to change) influencing eating behavior that may shape diet quality during pregnancy. The impact of diet quality could very well extend beyond GWG to birth outcomes (e.g., macrosomia, low birthweight and pre-term delivery), but such outcomes were not investigated in the present study. Regardless of these limitations, this study was able to provide valuable insights into diet quality and the relationship with weigh gain during pregnancy. These results could inform the development of recommendations and prevention strategies to improve pregnancy outcome.

\section{Conclusions}

Overall, pregnant women in the current study had relatively low HEI scores and the total HEI score varied throughout pregnancy. Women who were overweight and obese had poorer HEI score during pregnancy compared to non-overweight/obese women. Diet quality was significantly associated with GWG and this association differed significantly between non-overweight/obese and overweight/obese women. Women with higher total HEI score in third trimester were at higher risk for excessive GWG, regardless of pre-pregnancy BMI. Assessment of diet quality and its association to GWG is needed to develop tailored interventions for pregnant women that ensure adequate diet quality and gestational weight gain through healthy food choices and micronutrient supplementation.

Supplementary Materials: The following are available online at http://www.mdpi.com/1660-4601/16/19/3735/s1, Table S1: Component score and total score for Healthy Eating Index (HEI) for Malaysians among the respondents.

Author Contributions: Z.M.S. and H.Y.Y. conceptualized and designed the study; Z.M.S, guided data analysis, interpretation, and finalized the draft; H.Y.Y. collected and analyzed data, prepared original draft; B.N.M.Y., Z.R. contributed to the development of study protocol, read and approved the manuscript. E.M.v.d.B., J.B., and Y.Y.S.T. read and approved the manuscript. All authors read and approved the final version of the manuscript.

Funding: This research was funded by DANONE DUMEX (M) SDN BHD. The funders had no role in the design of the study; in the collection, analyses, or interpretation of data; in the writing of the manuscript, or in the decision to publish the results.

Acknowledgments: The authors would like thank all participants in the SECOST study for their time and cooperation and acknowledge the nurses, and staff in MCH clinics of Seremban district, Negeri Sembilan for their assistance during data collection.

Conflicts of Interest: J.B., and E.M.v.d.B. are employees of Danone Nutricia Research and Y.Y.S.T. of Danone Dumex Malaysia. The authors declare no conflict of interest.

\section{References}

1. Japan Society for the Study of Obesity. Obesity in Pregnant Women (in Japanese) Japan Society for the Study of Obesity (JSSO) Guideline 2016; Japan Society for the Study of Obesity: Osaka, Japan, 2016.

2. Watanabe, H.; Kabeyama, K.; Sugiyama, T.; Fukuoka, H. A Review of Inadequate and Excessive Weight Gain in Pregnancy. Curr. Women's Health Rev. 2009, 5, 186-192. [CrossRef]

3. Nucci, L.B.; Duncan, B.B.; Mengue, S.S.; Branchtein, L.; Shimidt, M.I.; Fleck, E.T. Assessment of weight gain during pregnancy in general prenatal care services in Brazil. Cad. Saúde Pública 2001, 17, 1367-1374. [CrossRef] [PubMed]

4. Yong, H.Y.; Mohd Shariff, Z.; Koo, S.J.; Sa'ari, N.S. Pre-pregnancy body mass index, height and physical activity are associated with rate of gestational weight gain among Malaysian mothers. J. Obstet. Gynaecol. Res. 2016, 42, 1094-1101. [CrossRef] [PubMed]

5. Rozlan, N.; Majid, H.A.M.A.; Abas, S.S.; Danis, A.; Isa, K.A.M. The association of gestational weight gain and the effect on pregnancy outcome defined by BMI group among women delivered in Hospital Kuala Lumpur (HKL), Malaysia: A retrospective study. Asian J. Clin. Nutr. 2012, 4, 160-167. [CrossRef] 
6. Stotland, N.E.; Haas, J.S.; Brawarsky, P.; Jackson, R.A.; Fuentes-Afflick, E.; Escobar, G.J. Body mass index, provider advice, and target gestational weight gain. Obstet. Gynecol. 2005, 105, 633-638. [CrossRef] [PubMed]

7. Fransen, H.P.; Ocké, M.C. Indices of diet quality. Curr. Opin. Clin. Nutr. Metab. Care 2008, 11, 559-565. [CrossRef]

8. Kennedy, E.; Ohls, J.; Carlson, S.; Fleming, K. The Healthy Eating Index. Design and Applications. J. Am. Diet. Assoc. 1995, 95, 1103-1108. [CrossRef]

9. Cox, J.T.; Phelan, S.T. Nutrition During Pregnancy. Obstet. Gynecol. Clin. N. Am. 2008, 35, 369-383. [CrossRef]

10. Nash, D.M.; Gilliland, J.A.; Evers, S.E.; Wilk, P.; Campbell, M.K. Determinants of diet quality in pregnancy: Sociodemographic, pregnancy-specific, and food environment influences. J. Nutr. Educ. Behav. 2013, 45, 627-634. [CrossRef]

11. Blumfield, M.L.; Hure, A.J.; MacDonald-Wicks, L.; Smith, R.; Collins, C.E. A systematic review and meta-analysis of micronutrient intakes during pregnancy in developed countries. Nutr. Rev. 2013, 71, 118-132. [CrossRef]

12. Pick, M.E.; Edwards, M.; Moreau, D.; Ryan, E.A. Assessment of diet quality in pregnant women using the Healthy Eating Index. J. Am. Diet. Assoc. 2005, 105, 240-246. [CrossRef] [PubMed]

13. Han, C.Y.; Colega, M.; Quah, E.P.L.; Chan, Y.H.; Godfrey, K.M.; Kwek, K.; Saw, S.M.; Gluckman, P.D.; Chong, Y.S.; Chong, M.F.F. A healthy eating index to measure diet quality in pregnant women in Singapore: A cross-sectional study. BMC Nutr. 2015, 1, 39. [CrossRef]

14. Van Lee, L.; Chia, A.R.; Loy, S.L.; Colega, M.; Tham, E.K.H.; Cai, S.; Yap, F.; Godfrey, K.M.; Teoh, O.H.; Goh, D.; et al. Sleep and dietary patterns in pregnancy: Findings from the gusto cohort. Int. J. Environ. Res. Public Health 2017, 14, 1409. [CrossRef] [PubMed]

15. Dewi, R.K.; Khomsan, A.; Riyadi, H.; Diana, R. Dietary quality and nutritional status of pregnant women in Sumenep regency, Madura, Indonesia. Pak. J. Nutr. 2018, 17, 530-534. [CrossRef]

16. Tsigga, M.; Filis, V.; Hatzopoulou, K.; Kotzamanidis, C.; Grammatikopoulou, M.G. Healthy Eating Index during pregnancy according to pre-gravid and gravid weight status. Public Health Nutr. 2011, 14, 290-296. [CrossRef]

17. Savard, C.; Lemieux, S.; Carbonneau, É.; Provencher, V.; Gagnon, C.; Robitaille, J.; Morisset, A.S. Trimester-Specific Assessment of Diet Quality in a Sample of Canadian Pregnant Women. Int. J. Environ. Res. Public Health 2019, 16, 311. [CrossRef] [PubMed]

18. Moran, L.J.; Sui, Z.; Cramp, C.S.; Dodd, J.M. A decrease in diet quality occurs during pregnancy in overweight and obese women which is maintained post-partum. Int. J. Obes. 2013, 37, 704-711. [CrossRef]

19. Shin, D.; Bianchi, L.; Chung, H.; Weatherspoon, L.; Song, W.O. Is gestational weight gain associated with diet quality during pregnancy? Matern. Child Health J. 2014, 18, 1433-1443. [CrossRef]

20. Siega-Riz, A.M.; Viswanathan, M.; Moos, M.K.; Deierlein, A.; Mumford, S.; Knaack, J.; Thieda, P.; Lux, L.J.; Lohr, K.N. A systematic review of outcomes of maternal weight gain according to the Institute of Medicine recommendations: Birthweight, fetal growth, and postpartum weight retention. Am. J. Obstet. Gynecol. 2009, 201, 339.e1-339.e14. [CrossRef]

21. Koh, H.; Ee, T.X.; Malhotra, R.; Allen, J.C.; Tan, T.C.; Østbye, T. Predictors and adverse outcomes of inadequate or excessive gestational weight gain in an Asian population. J. Obstet. Gynaecol. Res. 2013, 39, 905-913. [CrossRef]

22. Catalano, P.M.; Mele, L.; Landon, M.B.; Ramin, S.M.; Reddy, U.M.; Casey, B.; Wapner, R.J.; Varner, M.W.; Rouse, D.J.; Thorp, J.M.; et al. Inadequate weight gain in overweight and obese pregnant women: What is the effect on fetal growth? Am. J. Obstet. Gynecol. 2014, 211, 137.e1-137.e7. [CrossRef] [PubMed]

23. Wen, T.; Lv, Y. Inadequate gestational weight gain and adverse pregnancy outcomes among normal weight women in China. Int. J. Clin. Exp. Med. 2015, 8, 2881-2886. [PubMed]

24. Margerison Zilko, C.E.; Rehkopf, D.; Abrams, B. Association of maternal gestational weight gain with short- and long-term maternal and child health outcomes. Am. J. Obstet. Gynecol. 2010, 202, 574.e1-574.e8. [CrossRef] [PubMed]

25. Li, N.; Liu, E.; Guo, J.; Pan, L.; Li, B.; Wang, P.; Liu, J.; Wang, Y.; Liu, G.; Baccarelli, A.A.; et al. Maternal prepregnancy body mass index and gestational weight gain on pregnancy outcomes. PLOS ONE 2013, 8, e82310. [CrossRef] 
26. Haugen, M.; Brantsæter, A.L.; Winkvist, A.; Lissner, L.; Alexander, J.; Oftedal, B.; Magnus, P.; Meltzer, H.M. Associations of pre-pregnancy body mass index and gestational weight gain with pregnancy outcome and postpartum weight retention: A prospective observational cohort study. BMC Pregnancy Childbirth 2014, 14, 201. [CrossRef] [PubMed]

27. Leddy, M.A.; Power, M.L.; Schulkin, J. The impact of maternal obesity on maternal and fetal health. Rev. Obstet. Gynecol. 2008, 1, 170-178. [PubMed]

28. Li, C.; Zeng, L.; Wang, D.; Dang, S.; Chen, T.; Watson, V.; Yan, H. Effect of maternal pre-pregnancy BMI and weekly gestational weight gain on the development of infants. Nutr. J. 2019, 18, 6. [CrossRef]

29. Yong, H.Y.; Mohd Shariff, Z.; Rejali, Z.; Mohd Yusof, B.N.; Yasmin, F.; Palaniveloo, L. Seremban Cohort Study (SECOST): A prospective study of determinants and pregnancy outcomes of maternal glycaemia in Malaysia. BMJ Open 2018, 8, e018321. [CrossRef] [PubMed]

30. First Data Bank. Nutritionist Pro TM; First Data Bank: San Bruno, CA, USA, 2005.

31. National Coordinating Committee on Food and Nutrition. Malaysian Dietary Guidelines 2010. A Report of the Technical Working Group on Nutritional Guidelines; Ministry of Health Malaysia: Putrajaya, Malaysia, 2010; Volume 1.

32. Kurotani, K.; Akter, S.; Kashino, I.; Goto, A.; Mizoue, T.; Noda, M.; Sasazuki, S.; Sawada, N.; Tsugane, S. Quality of diet and mortality among Japanese men and women: Japan Public Health Center based prospective study. BMJ 2016, 352, i1209. [CrossRef]

33. WHO. Physical Status: The Use and Interpretation of Anthropometry. Report of a WHO Expert Committee; WHO Technical Report Series No., 854; World Health Organization, Ed.; WHO: Geneva, Switzerland, 1995.

34. Institute of Medicine; Rasmussen, K.M.; Yaktine, A.L. Weight Gain During Pregnancy: Reexaming the Guidelines. Available online: http://www.nationalacademies.org/hmd/ \{\}/media/Files/Report\%20Files/2009/ Weight-Gain-During-Pregnancy-Reexamining-the-Guidelines/Report\%20Brief\%20-\%20Weight\%20Gain\% 20During\%20Pregnancy.pdf (accessed on 21 November 2012).

35. Chasan-Taber, L.; Schmidt, M.D.; Roberts, D.E.; Hosmer, D.; Markenson, G.; Freedson, P.S. Development and validation of a Pregnancy Physical Activity Questionnaire. Med. Sci. Sports Exerc. 2004, 36, 1750-1760. [CrossRef]

36. IBM Corp. IBM SPSS Statistics for Windows; Version 25.0; IBM Corp: Armonk, NY, USA, 2017.

37. Cohen, T.R.; Plourde, H.; Koski, K.G. Use of the Pregnancy Physical Activity Questionnaire (PPAQ) to identify behaviours associated with appropriate gestational weight gain during pregnancy. J. Phys. Act. Health 2013, 10, 1000-1007. [CrossRef]

38. Wojtyla, A.; Kapka-Skrzypczak, L.; Paprzycki, P.; Skrzypczak, M.; Bilinski, P. Epidemiological studies in Poland on effect of physical activity of pregnant women on the health of offspring and future generations-adaptation of the hypothesis development origin of health and diseases. Ann. Agric. Environ. Med. 2012, 19, 315-326.

39. Chandonnet, N.; Saey, D.; Alméras, N.; Marc, I. French pregnancy physical activity questionnaire compared with an accelerometer cut point to classify physical activity among pregnant obese women. PLoS ONE 2012, 7, e38818. [CrossRef] [PubMed]

40. Danielewicz, H.; Myszczyszyn, G.; Dębińska, A.; Myszkal, A.; Boznański, A.; Hirnle, L. Diet in pregnancy-More than food. Eur. J. Pediatr. 2017, 176, 1573-1579. [CrossRef] [PubMed]

41. Tielemans, M.J.; Garcia, A.H.; Santos, A.P.; Bramer, W.M.; Luksa, N.; Luvizotto, M.J.; Moreira, E.; Topi, G.; De Jonge, E.A.L.; Visser, T.L.; et al. Macronutrient composition and gestational weight gain: A systematic review. Am. J. Clin. Nutr. 2016, 103, 83-99. [CrossRef] [PubMed]

42. Diemert, A.; Lezius, S.; Pagenkemper, M.; Hansen, G.; Drozdowska, A.; Hecher, K.; Arck, P.; Zyriax, B.C. Maternal nutrition, inadequate gestational weight gain and birth weight: Results from a prospective birth cohort. BMC Pregnancy Childbirth 2016, 16, 224. [CrossRef] [PubMed]

43. McGowan, C.A.; Walsh, J.M.; Byrne, J.; Curran, S.; McAuliffe, F.M. The influence of a low glycemic index dietary intervention on maternal dietary intake, glycemic index and gestational weight gain during pregnancy: A randomized controlled trial. Nutr. J. 2013, 12, 140. [CrossRef] [PubMed]

44. Crivellenti, L.C.; Zuccolotto, D.C.C.; Sartorelli, D.S. Development of a Diet Quality Index Adapted for Pregnant Women. Rev. Saude Publica 2018, 52, 59. [CrossRef] [PubMed]

45. Grandy, M.; Snowden, J.M.; Boone-Heinonen, J.; Purnell, J.Q.; Thornburg, K.L.; Marshall, N.E. Poorer maternal diet quality and increased birth weight. J. Matern. Neonatal Med. 2018, 31, 1613-1619. [CrossRef] 
46. Shahar, S.; Jan Bin Jan Mohamed, H.; de Los Reyes, F.; Amarra, M.S. Adherence of Malaysian Adults' Energy and Macronutrient Intakes to National Recommendations: A Review and Meta-Analysis. Nutrients 2018, 10, 1584. [CrossRef] [PubMed]

47. Rezali, F.W.; Chin, Y.S.; Shariff, Z.M.; Mohd Yusof, B.N.; Sanker, K.; Woon, F.C. Evaluation of diet quality and its associated factors among adolescents in Kuala Lumpur, Malaysia. Nutr. Res. Pract. 2015, 9, 511-516. [CrossRef] [PubMed]

48. O'Neil, A.; Quirk, S.E.; Housden, S.; Brennan, S.L.; Williams, L.J.; Pasco, J.A.; Berk, M.; Jacka, F.N. Relationship between diet and mental health in children and adolescents: A systematic review. Am. J. Public Health 2014, 104, e31-e42. [CrossRef] [PubMed]

49. Quirk, S.E.; Williams, L.J.; O’Neil, A.; Pasco, J.A.; Jacka, F.N.; Housden, S.; Berk, M.; Brennan, S.L. The association between diet quality, dietary patterns and depression in adults: A systematic review. BMC Psychiatry 2013, 13, 175. [CrossRef] [PubMed]

50. Lutz, L.J.; Gaffney-Stomberg, E.; Williams, K.W.; McGraw, S.M.; Niro, P.J.; Karl, J.P.; Cable, S.J.; Cropper, T.L.; McClung, J.P. Adherence to the Dietary Guidelines for Americans Is Associated with Psychological Resilience in Young Adults: A Cross-Sectional Study. J. Acad. Nutr. Diet. 2017, 117, 396-403. [CrossRef] [PubMed]

51. Sánchez-Villegas, A.; Henríquez-Sánchez, P.; Ruiz-Canela, M.; Lahortiga, F.; Molero, P.; Toledo, E.; Martínez-González, M.A. A longitudinal analysis of diet quality scores and the risk of incident depression in the SUN Project. BMC Med. 2015, 13, 197. [CrossRef] [PubMed]

52. Laraia, B.A.; Bodnar, L.M.; Siega-Riz, A.M. Pregravid body mass index is negatively associated with diet quality during pregnancy. Public Health Nutr. 2007, 10, 920-926. [CrossRef] [PubMed]

53. Bodnar, L.M.; Siega-Riz, A.M. A Diet Quality Index for Pregnancy detects variation in diet and differences by sociodemographic factors. Public Health Nutr. 2002, 5, 801-809. [CrossRef] [PubMed]

54. Rifas-Shiman, S.L.; Rich-Edwards, J.W.; Kleinman, K.P.; Oken, E.; Gillman, M.W. Dietary Quality during Pregnancy Varies by Maternal Characteristics in Project Viva: A US Cohort. J. Am. Diet. Assoc. 2009, 109, 1004-1011. [CrossRef] [PubMed]

55. Yuan, Y.Q.; Li, F.; Dong, R.H.; Chen, J.S.; He, G.S.; Li, S.G.; Chen, B. The development of a chinese healthy eating index and its application in the general population. Nutrients 2017, 9, 977. [CrossRef]

56. Bodnar, L.M.; Simhan, H.N.; Parker, C.B.; Meier, H.; Mercer, B.M.; Grobman, W.A.; Haas, D.M.; Wing, D.A.; Hoffman, M.K.; Parry, S.; et al. Racial or Ethnic and Socioeconomic Inequalities in Adherence to National Dietary Guidance in a Large Cohort of US Pregnant Women. J. Acad. Nutr. Diet. 2017, 117, 867-877.e3. [CrossRef]

57. Rodríguez-Bernal, C.L.; Rebagliato, M.; Iñiguez, C.; Vioque, J.; Navarrete-Muñoz, E.M.; Murcia, M.; Bolumar, F.; Marco, A.; Ballester, F. Diet quality in early pregnancy and its effects on fetal growth outcomes: The infancia y medio ambiente (childhood and environment) mother and child cohort study in Spain. Am. J. Clin. Nutr. 2010, 91, 1659-1666. [CrossRef] [PubMed]

58. Emond, J.A.; Karagas, M.R.; Baker, E.R.; Gilbert-Diamond, D. Better diet quality during pregnancy is associated with a reduced likelihood of an infant born small for gestational age: An analysis of the prospective New Hampshire birth cohort study. J. Nutr. 2018, 148, 22-30. [CrossRef] [PubMed]

(C) 2019 by the authors. Licensee MDPI, Basel, Switzerland. This article is an open access article distributed under the terms and conditions of the Creative Commons Attribution (CC BY) license (http://creativecommons.org/licenses/by/4.0/). 